\title{
Arbuscular mycorrhizal fungus improves the yield and quality of Lactuca sativa in an organic farming system
}

\author{
Patai Charoonnart $^{\mathrm{a}, \mathrm{b}}$, Kanogwan Seraypheap ${ }^{\mathrm{a}}$, Supachitra Chadchawan ${ }^{\mathrm{a}}$, \\ Teerada Wangsomboondee ${ }^{\text {a,* }}$ \\ a Centre of Excellence in Environmental and Plant Physiology Research Unit, Department of Botany, \\ Faculty of Science, Chulalongkorn University, Bangkok 10330 Thailand \\ b Programme of Biological Science, Faculty of Science, Chulalongkorn University, \\ Bangkok 10330 Thailand
}

*Corresponding author, e-mail: teerada.w@chula.ac.th

\begin{abstract}
Arbuscular mycorrhizal fungi have been reported to enhance the growth of many crop plants. This study examines the effect of Funneliformis mosseae, a type of arbuscular mycorrhizal fungus (AMF), on the growth of butterhead lettuce in organic cultivation. Lettuces were inoculated with 50 spores of $F$. mosseae to determine their physiological and biochemical characters compared to uninoculated lettuces in an abandoned field. After 60 days of growth, the AMF-inoculated plants had significantly more leaves (on average, 19.4) and greater leaf fresh weight (on average, $30.4 \mathrm{~g}$ ) than for the no-AMF treatment which had 15.8 leaves with a total weight of $14.5 \mathrm{~g}$. Net photosynthesis and the chlorophyll $a$ content were higher in the AMF-inoculated plants than in the control plants. The rhizosphere soil of 60-day-old AMF-inoculated butterhead lettuce showed higher organic matter, available phosphorus content, and exchangeable potassium content. The plants in the AMF treatment showed higher total nitrogen, phosphorus, and potassium contents in leaf and root tissues than the control plants. Antioxidant capacity was analysed by quantifying catalase and ascorbate peroxidase activities, ascorbic acid content, and carotenoid content. All of these parameters tended to be higher in the AMF treatment than in the control. The diphenylpicrylhydrazyl radical scavenging activity in AMF-inoculated plants (54\%) was twice that in the control plants (24\%). These results demonstrate that applying AMF is a cost-effective way to enhance the growth of organically farmed butterhead lettuce.
\end{abstract}

KEYWORDS: butterhead lettuce, Funneliformis mosseae, plant nutrition, photosynthesis, soil quality

\section{INTRODUCTION}

Lettuce (Lactuca sativa) is popular worldwide among health-conscious consumers because of its high nutritive value ${ }^{1}$. As lettuce is mostly consumed as fresh leaves, the organic farming system has excellent potential for lettuce cultivation in order to avoid accumulation of toxic substances derived from synthetic compounds. Lettuce cultivated in an organic system was reported to have a better nutritive value than those cultivated in conventional agricultural systems ${ }^{2}$. However, it is often difficult to cultivate plants organically, especially the first crop in abandoned areas, because of poor soil quality $^{3}$. Areas that have been periodically disturbed by natural events tend to have shallow, eroded, and/or degraded soils ${ }^{4}$. Thus appropriate soil management or amendments are required before cultivating the first crop in a new area.

One method to improve soil quality is to inocu- late microbes commonly found in soils of successful organic farms into new areas. Arbuscular mycorrhizal fungi (AMF) are a group of fungi often used in organic farming systems, and they have many reported advantages ${ }^{5}$. One of the most important characteristics of AMF is to improve the absorption of nutrients, especially phosphorus, from soil. Soil nutrients are taken up into the plant root via the AMF hyphae ${ }^{6}$. AMF also play an important role in stabilizing soil aggregates as they secrete glomalinlike proteins from the hyphae into soil ${ }^{7}$. Additionally, AMF affect the number of soil microbes, particularly plant growth promoting rhizobacteria (PGPR) and bacterial and fungal plant pathogens ${ }^{8}$. Hence, the use of AMF which may be associated with other soil microbes in organic farming has beneficial effects not only on crops by improving soil quality and increasing microbial community in soil, but also on the AMF themselves. For example, it was reported that the AMF in soils of organic 
farms were more numerous and diverse than soils of conventional farms, and that the extent of AMF colonization in plants was greater in organic farming systems ${ }^{9}$.

Even though the effectiveness of AMF has been recognized for many decades, limited information is available about the physiological and biochemical effects of each AMF isolate on each plant species. Specificity of the host-isolate interaction especially between butterhead and Glomus mosseae to promote growth in a pot experiment was demonstrated in the previous study ${ }^{10}$. Thus the objective of this study was to evaluate the effects of a Funneliformis mosseae (Nicolson \& Gerdemann) Walker \& Schuessler (recently renamed from Glomus mosseae Schenck \& Smith by Schüßler and Walker ${ }^{11}$ ) inoculated in a butterhead crop grown under natural field conditions in an organic farming system. The effects of an AMF on the growth, net photosynthesis, and nutrient absorption of butterhead lettuce were evaluated. The influence of the AMF on soil quality was determined. In addition, the nutritive quality of lettuce in terms of its antioxidant capacity, antioxidant enzyme activity, and the nature of nonenzymatic antioxidant compounds in lettuce tissues were analysed to determine whether the AMF affected plant qualities.

\section{MATERIALS AND METHODS}

\section{Study area}

The experiment was carried out at the Centre of Learning Network for the Region of Chulalongkorn University, Keang Koi District, Saraburi Province, Thailand. The study site was located at $14^{\circ} 52^{\prime} \mathrm{N}$, $101^{\circ} 02^{\prime} \mathrm{E}$, and altitude $47 \mathrm{~m}$ AMSL. This area has a tropical climate. The land was abandoned and nothing had been cultivated at the site for more than 10 years. The soil at the site was characterized as loam with a $\mathrm{pH}$ of 5.7-6.0. The experiment was performed in August to October 2014, when the average temperature and rainfall were $28.0^{\circ} \mathrm{C}$ $28.5^{\circ} \mathrm{C}$ and $87.4-225.0 \mathrm{~mm}$ per month, respectively (average annual rainfall $=1457 \mathrm{~mm}$ and annual temperature $=27.8^{\circ} \mathrm{C}$ ).

\section{Experimental design and treatments}

A completely randomized design was used with four replications and six subreplications. The experiment consisted of two treatments: uninoculated butterhead lettuce (control; no-AMF) and butterhead inoculated with 50 spores of Funneliformis mosseae (AMF) per plant. There were four plots $\left(1 \times 8 \mathrm{~m}^{2}\right)$ of soil mixed with coconut fibre substrate $(5 \mathrm{~kg} /$ plot) in each treatment with $0.5 \mathrm{~m}$ spacing between plots, making a total of eight plots, in random order. Seeds of butterhead lettuce (L. sativa) were purchased from ACK Hydrofarm Co., Ltd., Thailand, and germinated in seedling trays for 2 weeks before transplanting into each plot. Each plot contained two rows of plants with $0.35 \mathrm{~m}$ spacing between plants to obtain plant density at 5 plants $/ \mathrm{m}^{2}$. At transplantation, soil inoculum was mixed roughly with the soil at the point where each seedling was transplanted. The plants were watered at the rate 61 per row twice daily and cultivated for 60 days. No fertilizer was added to the soil during these experiments and weeds were managed manually.

\section{Plant growth measurement}

Six plants were randomly collected from each plot, and then leaves and roots were analysed separately. For leaves, the number, fresh weight, dry weight, length, and width were determined. For roots, the AMF colonization percentage at 2nd, 4th, 6th, and 8th week was calculated as described by Phillip and Hayman $^{12}$.

\section{Photosynthesis measurement}

Net photosynthesis, transpiration rate, intracellular $\mathrm{CO}_{2}$, and stomatal conductance were measured using a portable photosynthesis system (Li-cor 6400) on the biggest leaf (3rd or 4th leaf from outside) with a photosynthetic photon flux density of $800 \mu \mathrm{mol} \mathrm{m} \mathrm{m}^{-2} \mathrm{~s}^{-1}$ and $\mathrm{a} \mathrm{CO}_{2}$ concentration of $400 \mu \mathrm{mol} / \mathrm{mol}$ (obtained from a light response curve). Photosynthetic pigments, chlorophylls $a$ and $b$, were extracted from the same leaf in $80 \%$ acetone in the dark for $24 \mathrm{~h}$. Then, the absorbance of the acetone solution was measured using a spectrophotometer at $663.2,646.8$, and $470 \mathrm{~nm}$. The concentrations of chlorophyll $a$ and $b$ were calculated from the absorbance values as described by Porra ${ }^{13}$.

\section{Soil properties and plant nutrient analysis}

Three replications of rhizosphere soils were collected for analysis according to soil group: soil before transplanting, control soil at harvest time, and AMF-inoculated soil at harvest time. The soils were kept at room temperature until analysis. The physiochemical properties of the soils including $\mathrm{pH}$, organic matter $(\mathrm{OM})$, available phosphorus, and exchangeable potassium, magnesium, and calcium contents were determined. For plant samples, whole leaves and roots were separately oven-dried at $60^{\circ} \mathrm{C}$ for 3 days. Then, samples from each 
treatment were pooled and ground to powder before determining the total nitrogen, phosphorus, and potassium contents. Organic matter and available phosphorus were determined using the Walkley and Black method and the Bray II method, respectively ${ }^{14,15}$. Exchangeable potassium, calcium, and magnesium were extracted in $1 \mathrm{~N} \mathrm{NH}_{4} \mathrm{OAc}(\mathrm{pH} 7.0)$ and then quantified by atomic absorption spectrometry ${ }^{16}$. Total nitrogen in plant tissues was quantified by the semi-micro Kjeldahl method followed by distillation ${ }^{17}$. Total phosphorus in plant tissues was analysed using the vanadomolybdophosphoric acid yellow method. Total potassium in plant tissues was determined by atomic absorption spectrometry after digestion with concentrated nitric acid ${ }^{16}$.

\section{Antioxidant enzyme assays and quantification of non-enzymatic antioxidants}

To determine the effects of the AMF on the nutritive value of butterhead, the activity of the antioxidant enzymes catalase (CAT) and ascorbate peroxidase (APX), the contents of three non-enzymatic antioxidants (ascorbic acid (AA), phenolic compounds (PHE), and total carotenoids (CAR)), and the diphenylpicrylhydrazyl ( $\left.\mathrm{DPPH}^{\bullet}\right)$ free radical scavenging capacity in AMF-inoculated and control plants were determined. To measure the activity of enzymatic antioxidants, $1 \mathrm{~g}$ leaf tissue from 60day-old butterhead plants was ground in liquid $\mathrm{N}_{2}$ and then extracted in buffer $(50 \mathrm{mM}$ phosphate buffer, $\mathrm{pH}$ 7.0; 1\% (w/v) polyvinylpolypyrrolidone, $1 \mathrm{mg} / \mathrm{ml}$ dithiothreitol, and $100 \mathrm{mM}$ phenylmethylsulphonyl fluoride). The mixture was centrifuged at $10000 \mathrm{~g}$ for $10 \mathrm{~min}$ at $4^{\circ} \mathrm{C}$, and then the supernatant was collected and used to determine the activities of CAT and APX as described by Aebi ${ }^{18}$ and Nakano and Asada ${ }^{19}$, respectively.

To extract and quantify non-enzymatic antioxidants, AA was extracted with $6 \%$ metaphosphoric acid in $2 \mathrm{M}$ acetic acid and then quantified as described by Shin et $\mathrm{al}^{20}$. The absorbance of the AA assay mixture at $540 \mathrm{~nm}$ was determined and compared with a standard curve constructed using known concentrations of ascorbic acid. CAR was extracted from plant tissues by the same method as that used to extract total chlorophyll, and then the concentration was calculated as described by Sims and Gamon ${ }^{21}$. Methanol was used as the solvent to prepare the crude extract for the PHE and $\mathrm{DPPH}^{\bullet}$ assays. PHE was quantified using the Folin-Ciocalteu method. The absorbance of the mixture at $750 \mathrm{~nm}$ was used to calculate total PHE, which is expressed as mg gallic acid equivalents ${ }^{22}$.
Table 1 Growth parameters of 60-day-old butterhead lettuce cultivated in an organic farming system.

\begin{tabular}{lccccc}
\hline Treatment & Leaves & FW $(\mathrm{g})$ & DW $(\mathrm{g})$ & $\mathrm{W}(\mathrm{cm})$ & $\mathrm{L}(\mathrm{cm})$ \\
\hline no-AMF & 15.77 & 14.50 & 0.95 & 5.41 & 9.38 \\
AMF & 19.41 & 30.37 & 1.02 & 5.36 & 8.88 \\
$p$ value & $p<0.01$ & $p<0.01$ & NS & NS & NS \\
\hline
\end{tabular}

$\mathrm{NS}=$ No significant difference at $p<0.05$.

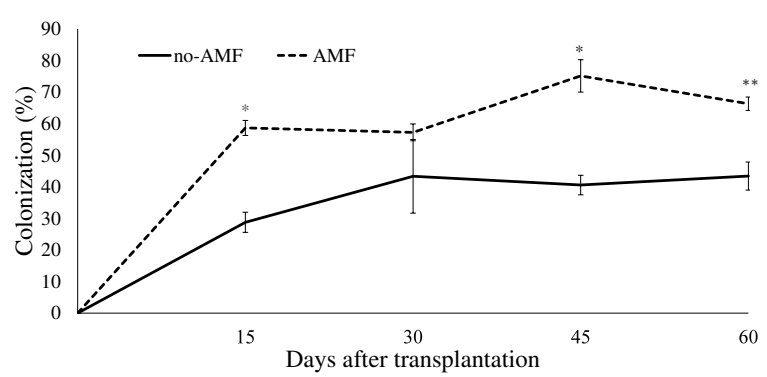

Fig. 1 Colonization percentage of 60-day-old butterhead lettuce cultivated in an organic farming system. (*, **: significant difference at $p<0.05, p<0.01$, respectively).

The change in the concentration of the free radical $\mathrm{DPPH}^{\bullet}$ was determined by measuring the decrease in absorbance at $515 \mathrm{~nm}$. The $\mathrm{DPPH}^{\bullet}$ radical scavenging activity is expressed as the percentage inhibition of this reaction ${ }^{23}$.

\section{Statistical analysis}

The data for soil properties were subjected to ANOVA and means were compared using the Least Significance Difference test using SPSS 20.0. Data for growth parameters, photosynthetic activity, antioxidant enzyme activity, and antioxidant compound content were analysed by $t$-test. All statistical analyses were tested at $95 \%$ or $99 \%$ confidence intervals.

\section{RESULTS}

\section{Plant growth}

Compared with control plants, the plants inoculated with the AMF had significantly more leaves and approximately double the leaf fresh weight at harvest (Table 1). However, the leaf dry weight, leaf width, and leaf length were not significantly different between the AMF-inoculated and control plants. The colonization percentage in the roots of AMF-inoculated plants was twice that in the roots of control plants by the end of the 60-day growth period (Fig. 1), with significant differences at weeks 2,6 , and 8 . 
Table 2 Photosynthetic parameters and photosynthetic pigments contents in 60-day-old butterhead lettuce cultivated in an organic farming system.

\begin{tabular}{|c|c|c|c|c|c|c|c|}
\hline \multirow[t]{2}{*}{ Treatment } & \multicolumn{4}{|c|}{ Photosynthetic parameters } & \multicolumn{3}{|c|}{ Pigments } \\
\hline & net photo ${ }^{a}$ & $\mathrm{C}_{\mathrm{i}}^{\mathrm{b}}$ & $\operatorname{Tr} \mathrm{mmol}^{\mathrm{c}}$ & Cond. $^{\mathrm{d}}$ & Total Chl ${ }^{\mathrm{e}}$ & Chl $a^{\mathrm{e}}$ & Chl $b^{\mathrm{e}}$ \\
\hline no-AMF & 4.27 & 208.18 & 0.71 & 0.04 & 520.67 & 374.17 & 146.49 \\
\hline AMF & 6.12 & 174.43 & 0.85 & 0.04 & 602.58 & 437.05 & 165.53 \\
\hline$p$ value & $p<0.01$ & NS & $p<0.05$ & NS & $p<0.05$ & $p<0.05$ & NS \\
\hline
\end{tabular}

net photo $=$ net photosynthesis; $\mathrm{C}_{\mathrm{i}}=$ intercellular $\mathrm{CO}_{2}$; $\operatorname{Tr}$ mmol = transpiration rate; Cond. = stomatal conductance; $\mathrm{Chl}=$ chlorophyll. $\mathrm{NS}=$ No significant difference at $p<0.05$.

${ }^{\mathrm{a}}\left(\mu \mathrm{mol} \mathrm{CO} \mathrm{m}^{-2} \mathrm{~s}^{-1}\right) ;{ }^{\mathrm{b}}\left(\mu \mathrm{mol} \mathrm{CO}_{2} \mathrm{~mol}^{-1}\right) ;{ }^{\mathrm{c}}\left(\mathrm{mmol} \mathrm{H}_{2} \mathrm{O} \mathrm{m}^{-2} \mathrm{~s}^{-1}\right) ;{ }^{\mathrm{d}}\left(\mathrm{mol} \mathrm{H}_{2} \mathrm{O} \mathrm{m}^{-2} \mathrm{~s}^{-1}\right){ }^{\mathrm{e}}\left(\mu \mathrm{g} \mathrm{ml}^{-1} \mathrm{~g}^{-1} \mathrm{FW}\right)$.

Table 3 Properties of rhizosphere soil before and 60 days after transplanting butterhead lettuce in an organic farming system.

\begin{tabular}{llccccc}
\hline Treatments & $\mathrm{pH}$ & OM $(\%)$ & AvP $(\mathrm{mg} / \mathrm{kg})$ & ExK $(\mathrm{mg} / \mathrm{kg})$ & ExCa $(\mathrm{mg} / \mathrm{kg})$ & ExMg $(\mathrm{mg} / \mathrm{kg})$ \\
\hline Before & $5.9^{\mathrm{a}}$ & $1.85^{\mathrm{a}}$ & $2.00^{\mathrm{a}}$ & $181.33^{\mathrm{a}}$ & $1469.00^{\mathrm{c}}$ & $240.00^{\mathrm{b}}$ \\
no-AMF & $6.2^{\mathrm{ab}}$ & $2.40^{\mathrm{ab}}$ & $3.67^{\mathrm{a}}$ & $223.00^{\mathrm{a}}$ & $1202.67^{\mathrm{a}}$ & $212.67^{\mathrm{a}}$ \\
AMF & $6.4^{\mathrm{b}}$ & $3.07^{\mathrm{b}}$ & $12.33^{\mathrm{b}}$ & $238.67^{\mathrm{a}}$ & $1362.67^{\mathrm{b}}$ & $224.00^{\mathrm{a}}$ \\
\hline
\end{tabular}

$\mathrm{OM}=$ Organic matter; AvP = Available phosphorus; ExK = Exchangeable potassium; ExCa = Exchangeable calcium; $\mathrm{ExMg}=$ Exchangeable magnesium. Different letters within a column represent significant difference at $p<0.05$.

\section{Photosynthesis measurement}

Net photosynthesis and transpiration rate were higher in AMF-inoculated plants than in control plants (Table 2). The intercellular $\mathrm{CO}_{2}$ concentration tended to be lower in AMF-inoculated plants than in control plants, but the difference was not statistically significant. The stomatal conductance was equivalent in the AMF-inoculated plants and the control plants $\left(0.04 \mathrm{~mol} \mathrm{H}_{2} \mathrm{O} \mathrm{m}^{-2} \mathrm{~s}^{-1}\right)$.

The total chlorophyll content was significantly higher in the AMF-inoculated plants than in the control plants (Table 2). Subsequent analysis showed that only the chlorophyll $a$ content, and not the chlorophyll $b$ content, was significantly higher in the AMF-inoculated plants.

\section{Soil properties and plant nutrient contents}

The rhizosphere soil $\mathrm{pH}$ and OM percentage of both the AMF treatment and the control increased by the harvesting time, but only the AMF soil had significant differences in $\mathrm{pH}$ value and $\mathrm{OM}$ percentage compared with that before transplantation (Table 3). The OM percentage in the AMF soil was approximately 1.5 -fold higher than that before transplantation and 0.5 -fold higher than that of the control soil at harvest. The available phosphorus content in AMF soil at harvest was $12.33 \mathrm{mg} / \mathrm{kg}$ soil, markedly higher than that before transplantation ( $2 \mathrm{mg} / \mathrm{kg}$ soil) and that in the no-AMF control at harvest $(3.67 \mathrm{mg} / \mathrm{kg}$ soil). No significant difference in exchangeable potassium content was detected between the AMF treatment and the control at harvest. The exchangeable magnesium and calcium contents in soil significantly decreased in both the AMF treatment and the control during the experiment. Only the exchangeable calcium content in soil was significantly higher in the AMF treatment than in the control.

The concentrations of nitrogen, phosphorus, and potassium were significantly higher in the leaf than in the root, and higher in the leaves and roots of plants in the AMF treatment compared to the control plants (Fig. 2). The levels of nitrogen, phosphorus, and potassium in the leaf were $17 \%, 6 \%$, and 5\% higher, respectively, in the AMF treatment as compared to the control. In the root, the levels of nitrogen, phosphorus, and potassium were $38 \%$, $26 \%$, and $20 \%$, higher, respectively, in the AMF treatment than in the control.

\section{Antioxidant enzyme activities and antioxidant compound contents}

The activities of CAT and APX increased after AMF inoculation (Table 4), but the increases were not statistically significant. The total free radical scavenging activity, expressed as the percentage inhibition of the $\mathrm{DPPH}^{\bullet}$ reaction, was 2 -fold higher in the AMF treatment than in the control (Table 4). The levels of the non-enzymatic antioxidants AA and CAR tended to increase in plants in the AMF 
Table 4 Enzymatic and non-enzymatic antioxidants in 60-day-old butterhead lettuce cultivated in an organic farming system.

\begin{tabular}{|c|c|c|c|c|c|c|}
\hline \multirow[t]{2}{*}{ Treatment } & \multicolumn{2}{|c|}{ Antioxidant enzymes } & \multicolumn{4}{|c|}{ Non-enzymatic antioxidants } \\
\hline & CAT (units) ${ }^{\dagger}$ & APX (units) ${ }^{\dagger}$ & $\mathrm{AA}^{\mathrm{a}}$ & $\mathrm{PHE}^{\mathrm{a}}$ & $\mathrm{CAR}^{\mathrm{b}}$ & DPPH (\%) \\
\hline No-AMF & 35.23 & 87.37 & 0.31 & 0.50 & 58.49 & 24.12 \\
\hline $\mathrm{AMF}$ & 39.30 & 95.05 & 0.33 & 0.47 & 64.37 & 53.85 \\
\hline$p$ value & NS & NS & NS & NS & NS & $p<0.01$ \\
\hline
\end{tabular}

$\mathrm{CAT}=$ catalase $; \mathrm{APX}=$ ascorbate peroxidase; $\mathrm{AA}=$ ascorbic acid; $\mathrm{PHE}=$ phenolic content; $\mathrm{CAR}=$ carotenoid; $\mathrm{DPPH}=\mathrm{DPPH}^{\bullet}$ scavenging; $\mathrm{NS}=$ no significant difference at $p<0.05 . \quad{ }^{\text {a }}\left(\mathrm{mg} \mathrm{g}^{-1} \mathrm{FW}\right) ;{ }^{\mathrm{b}}\left(\mu \mathrm{g} \mathrm{ml}^{-1} \mathrm{~g}^{-1} \mathrm{FW}\right)$.

$\dagger$ One unit is defined as the amount of enzyme that converts 1 mol substrate per min.
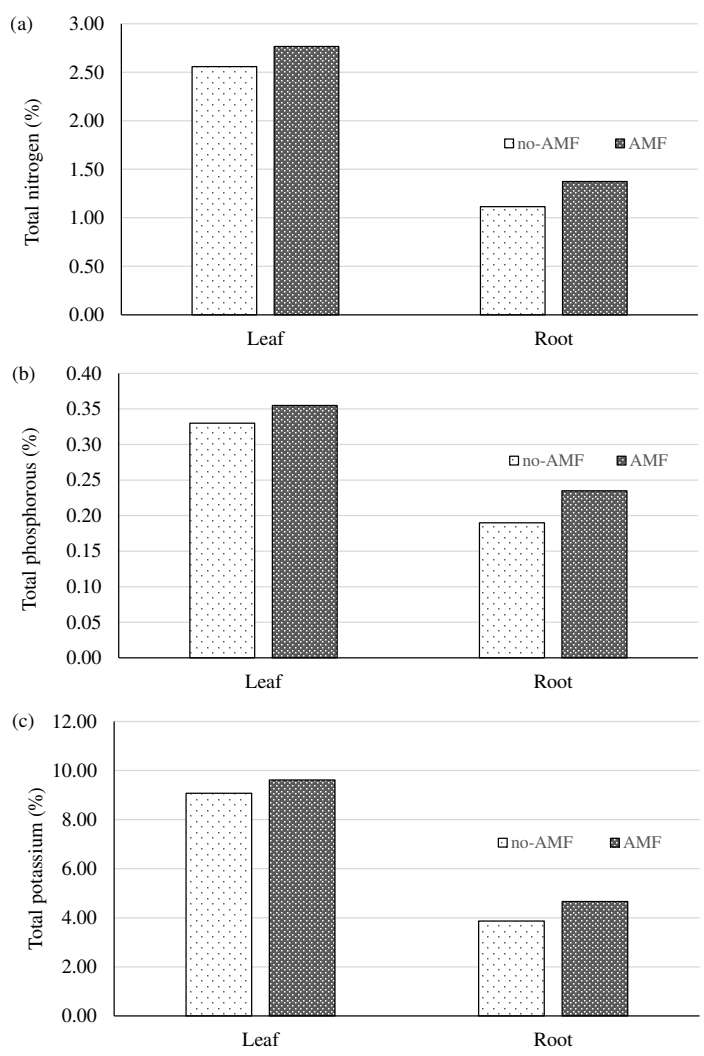

Fig. 2 (a) Total nitrogen, (b) phosphorus, and (c) potassium contents in 60-day-old butterhead lettuce inoculated with Funneliformis mosseae (AMF) or not inoculated (noAMF) and cultivated in an organic farming system. (A composite sample of each treatment is presented).

treatment, but these increases were not statistically significant.

\section{DISCUSSION}

The results of this study provided evidence that AMF inoculation increased the yield of butterhead lettuce cultivated in an area that had been abandoned for
10 years. Although the benefits of AMF on plant growth have been reported since the 1980s, most studies have concluded that the effects of AMF on plant growth and development are complex, and rely on the interaction between the host and the $\mathrm{AMF}$, and on the genotypes of both organisms ${ }^{24}$. In the present study, specificity of butterhead lettuce inoculated with $F$. mosseae showed greater yield, which was attributed to greater fresh weight and more leaves at harvest. The greater fresh weight of AMF-inoculated butterhead may be explained by the higher water content in the leaves of the AMF plants. Allen $^{25}$ reported that AMF directly absorbed and transferred soil water to the root of the inoculated plant. Other studies have shown that AMF extract soil moisture via their hyphae and transport it to the $\operatorname{root}^{26}$, which may result in higher leaf water content. Hence the yield improvement is necessary for organic farmers to adapt this AMF amendment in cultivation.

The mechanisms by which the AMF increased plant growth were clarified by the increase in photosynthetic activity and chlorophyll contents. The effects of AMF on photosynthesis however differ among plant species and AMF isolates. Augé reported that different species of AMF resulted in different photosynthetic responses under various abiotic stress conditions. For example, colonization with $G$. fasciculatum tended to increase stomatal conductance in many plants such as Medicago sativa while colonization with only $G$. mosseae had less effect on this parameter ${ }^{27}$. In the present study, the AMF did not affect the stomatal conductance or intercellular $\mathrm{CO}_{2}$ of butterhead lettuce.

Several studies have reported that AMF increase the photosynthetic rate and the chlorophyll content in various host plants ${ }^{28,29}$, including several lettuce varieties in Spain ${ }^{30}$. The increased chlorophyll content was suggested to result from the AMFinduced increase in the uptake of nutrients, espe- 
cially magnesium, which is an important component of chlorophyll ${ }^{31}$ and increase the levels of core proteins of photosystem I and II and the lightharvesting complex II in Indica rice, leading to increased photosynthetic capacity ${ }^{32,33}$. The higher available phosphorus content in AMF-inoculated soil was suggested as another important factor in increasing photosynthesis in lettuce, by increasing the amount of ATP available to fuel $\mathrm{CO}_{2}$ assimilation in the Calvin cycle ${ }^{34}$.

The rhizosphere soil at harvest was less acidic in the AMF treatment than in the control, compared with the $\mathrm{pH}$ before transplanting. AMF were reported to neutralize soil $\mathrm{pH}$ by consuming $\mathrm{H}^{+}$ or by secreting organic substances ${ }^{35}$. Increase in organic matter and level of available phosphorus in soil containing F. mosseae facilitated the growth of butterhead lettuce in this abandon area and was useful for organic farming system. The ability of AMF to absorb nutrients from soil, and hence, promote plant growth, depends on the AMF species. For example, G. mosseae was shown to absorb nutrients from soil in a wide $\mathrm{pH}$ range, in both alkaline and calcareous soils ${ }^{36}$. The ability to increase available phosphorus levels is a significant and unique characteristic of AMF, and results from the production and secretion of phosphatase, which converts phosphorus from an inactive form into the active form, phosphate ${ }^{37}$. As the soil properties improved, the contents of major nutrients in the plant also increased. These increases were more evident in the root than in the leaf. This could be related to the fact that lettuce is a short-lived plant with a growth period of less than 60 days, and nutrient contents in the leaf are more strongly affected by AMF in longerlived plants ${ }^{38}$. This AMF species was also shown to associate with some PGPR such as Pseudomonas and Bacillus. These bacteria living on or inside the AMF spore wall are beneficial to plants ${ }^{39}$. Such PGPR are responsible for the decomposition of both inactive and active soil organic matter ${ }^{40}$. Thus the increase in organic matter in the AMF-inoculated soil could be due to larger populations of these PGPR. These bacteria can transform various soil nutrients into available forms that the plant root and fungus can take up.

In the present study, the activities of CAT and APX did not increase after AMF inoculation, contrary to the results of several other studies. Blilou et $\mathrm{al}^{41}$ showed that $G$. mosseae inoculation increased the activities of CAT and APX in tobacco roots, but these increases were transient. In that study, the highest activity of both enzymes coincided with the entry of the AMF appressoria into the plant root, after which the activity of both enzymes decreased over time. Increased activities of these antioxidant enzymes reflected the defence mechanism of the plant to infection by the fungus ${ }^{42}$. The overall antioxidant capacity can be measured as the percentage inhibition of the $\mathrm{DPPH}^{\bullet}$ free radical reaction, representing radical quenching kinetics ${ }^{43}$. Butterhead lettuce inoculated with $F$. mosseae contained high $\mathrm{DPPH}^{\bullet}$ scavenging activity which increases value of lettuce and is beneficial to consumers. It has been reported recently that AMF can increase the $\mathrm{DPPH}^{\bullet}$ scavenging activity of many plants, including cyclamen and onion ${ }^{44,45}$. In the present study, the levels of the non-enzymatic antioxidants AA and CAR were similar between the control and the AMF treatment. However, because the water content was higher in the leaves of the AMFinoculated butterhead lettuces, probably there was some dilution of these compounds. Moreover, the AMF may have led to changes in the levels of other antioxidant substances that increased the $\mathrm{DPPH}^{\circ}$ scavenging activity such as superoxide dismutase ${ }^{46}$. Further studies should be conducted to clarify the mechanisms by which the AMF increased the total antioxidant activity of butterhead lettuce.

The results of the present study represented the specificity between F. mosseae as inoculum and butterhead lettuce to increase both the quantity and quality of the crop in organic cultivation system. After an AMF is introduced into a planting area, it can continuously reproduce as long as it has a compatible plant host. Thus the presence of the AMF isolate in soil not only benefited the first crop, but can also be expected to improve the growth of subsequent crops at this site. The AMF isolate can be developed to be a bio-fertilizer that farmers can propagate the spores and consequently reduce their cost for the next crop ${ }^{47}$.

Acknowledgements: This study was financially supported by the 90th Year Anniversary of Chulalongkorn University Fund (the Ratchadaphiseksomphot Endowment Fund) and partially supported by the Higher Education Research Promotion and National Research University Project of Thailand, Office of the Higher Education Commission (WCU-019-FW-57). The first author was supported by a Chulalongkorn University Graduate Scholarship to commemorate the 72nd anniversary of His Majesty King Bhumibol Adulyadej. The authors thank the staff of the Centre of Learning Network for the Region of Chulalongkorn University for their support. 


\section{REFERENCES}

1. Llorach R, Martínez-Sánchez A, Tomás-Barberán FA, Gil MI, Ferreres F (2008) Characterisation of polyphenols and antioxidant properties of five lettuce varieties and escarole. Food Chem 108, 1028-38.

2. Ismail A, Fun CS (2003) Determination of vitamin $\mathrm{C}, \beta$-carotene and riboflavin contents in five green vegetables organically and conventionally grown. Malays J Nutr 9, 31-9.

3. Brouwer F, Rheenen TV, Djillion SD, Elgersma AM (2008) Sustainable Land Management: Strategies to Cope with the Marginalization of Agriculture, Edward Elgar Publishing Inc., Massachusetts, USA.

4. Pardini G, Gispert M, Dunjó G (2003) Runoff erosion and nutrient depletion in five Mediterranean soils of NE Spain under different land use. Sci Total Environ 309, 213-24.

5. Gosling P, Hodge A, Goodlass G, Bending GD (2006) Arbuscular mycorrhizal fungi and organic farming. Agr Ecosyst Environ 113, 17-35.

6. Satter MA, Hanafi MH, Mahmud TMM, Azizah H (2006) Influence of arbuscular mycorrhiza and phosphate rock on uptake of major nutrients by Acacia mangium seedlings on degraded soil. Biol Fertil Soils 42, 345-9.

7. Rillig MC, Wright SF, Eviner VT (2002) The role of arbuscular mycorrhizal fungi and glomalin in soil aggregation: comparing effects of five plant species. Plant Soil 238, 325-33.

8. Gianinazzi S, Gollotte A, Binet MN, van Tuinen D, Redecker D, Wipf D (2010) Agroecology: the key role of arbuscular mycorrhizas in ecosystem services. Mycorrhiza 20, 519-30.

9. Oehl F, Sieverding E, Mäder P, Dubois D, Ineichen K, Boller T, Wiemken A (2004) Impact of long-term conventional and organic farming on the diversity of arbuscular mycorrhizal fungi. Oecologia 138, 574-83.

10. Charoonnart P, Seraypheap K, Chadchawan S, Wangsomboondee $T$ (2016) Increasing butterhead lettuce yield using organic methods and application of arbuscular mycorrhizal fungi. Int $J$ Veg Sci 22, 520-9.

11. Schüßler A, Walker C (2010) The Glomeromycota: A Species List with New Families and New Genera, The Royal Botanic Garden Kew, Botanische Staatssammlung Munich, and Oregon State Univ.

12. Phillip JM, Hayman DS (1970) Improved procedures for clearing roots and staining parasitic and vesicular-arbuscular mycorrhizal fungi for rapid assessment of infection. Trans Br Mycol Soc 55, 158-61.

13. Porra RJ (2002) The chequered history of the development and use of simultaneous equations for the accurate determination of chlorophylls $a$ and $b$. Photosynth Res 73, 149-56.

14. Bray RH, Kurtz LT (1945) Determination of total, organic, and available forms of phosphorus in soils. Soil Sci 59, 39-46.
15. Nelson DW, Sommers LE (1996) Total carbon, organic carbon, and organic matter. In: Methods of Soil Analysis. Part 3: Chemical Methods, SSSA Book Series no 5, Soil Science Society of America, Wisconsin, pp 961-1010.

16. Jackson ML (1958) Soil Chemical Analysis, Prentice Hall, New Jersey.

17. Motsara MR, Roy RN (2008) Guide for Laboratory Establishment for Plant Nutrient Analysis, Food and Agriculture Organization of the United Nations, Rome, Italy.

18. Aebi H (1984) Catalase in vitro. Meth Enzymol 105, 121-6.

19. Nakano Y, Asada K (1981) Hydrogen peroxide is scavenged by ascorbate-specific peroxidase in spinach chloroplasts. Plant Cell Physiol 22, 867-80.

20. Shin Y, Liu RH, Nock JF, Holliday D, Watkins CB (2007) Temperature and relative humidity effects on quality, total ascorbic acid, phenolics and flavonoid concentrations, and antioxidant activity of strawberry. Postharvest Biol Tech 45, 349-57.

21. Sims DA, Gamon JA (2002) Relationships between leaf pigment content and spectral reflectance across a wide range of species, leaf structures and developmental stages. Rem Sens Environ 81, 337-54.

22. Choi Y, Lee SM, Chun J, Lee HB, Lee J (2006) Influence of heat treatment on the antioxidant activities and polyphenolic compounds of Shiitake (Lentinus edodes) mushroom. Food Chem 99, 381-7.

23. Yu L, Perret J, Harris M, Wilson J, Haley S (2003) Antioxidant properties of bran extracts from "Akron" wheat grown at different locations. J Agr Food Chem 51, 1566-70.

24. Buam C, El-Tohamy W, Gruda N (2015) Increasing the productivity and product quality of vegetable crops using arbuscular mycorrhizal fungi: a review. Sci Hort 187, 131-41.

25. Allen MF (1982) Influence of vesicular-arbuscular mycorrhizae on water movement through Bouteloua gracilis (H.B.K.) Lag ex Steud. New Phytol 91, 191-6.

26. Hardie K, Leyton L (1981) The influence of vesiculararbuscular mycorrhiza on growth and water relations of red clover. I. In phosphate deficient soil. New Phytol 89, 599-608.

27. Augé RM (2001) Water relations, drought and vesicular-arbuscular mycorrhizal symbiosis. Mycorrhiza 11, 3-42.

28. Haneef I, Faizan S, Perveen R, Kausar S (2013) Role of arbuscular mycorrhizal fungi on growth and photosynthetic pigments in (Coriandrum sativum L.) grown under cadmium stress. World J Agr Sci 9, 245-50.

29. Mohebi-Anabat M, Riahi H, Zanganeh S, Sadeghnezhad E (2015) Effects of arbuscular mycorrhizal inoculation on the growth photosynthetic pigments and soluble sugar of Crocus sativus (saffron) in autoclaved soil. Int J Agron Agr Res 6(4), 296-304. 
30. Baslam M, Garmendia I, Goicoechea N (2011) Arbuscular mycorrhizal fungi (AMF) improved growth and nutritional quality of greenhouse-grown lettuce. J Agr Food Chem 59, 5504-15.

31. Stobart AK, Griffiths WT, Ameen-Bukhari I, Sherwood RP (1985) The effect of $\mathrm{Cd}^{2+}$ on biosynthesis of chlorophyll in leaves of barley. Physiol Plant 63, 293-8.

32. Davies FT Jr, Potter JR, Linderman RG (1993) Drought resistance of mycorrhizal pepper plants independent of leaf $\mathrm{P}$ concentration - response in gas exchange and water relations. Physiol Plant 87, 45-53.

33. Kang Z, Li G, Huang J, Niu X, Zou H, Zang G, Wenwen Y, Wang G (2012) Photosynthetic and physiological analysis of the rice high-chlorophyll mutant $(G c)$. Plant Physiol Biochem 60, 81-7.

34. Luo HY, Lee SK, He J (2009) Integrated effects of root-zone temperatures and phosphorus levels on aeroponically-grown lettuce (Lactuca sativa L.) in the tropics. Open Hort J 2, 6-12.

35. Jolicoeur M, Germette S, Gaudette M, Perrier M, Bécard G (1998) Intracellular pH in arbuscular mycorrhizal fungi (a symbiotic physiological marker). Plant Physiol 116, 1279-88.

36. Khaliel AS (1990) The effect of two Glomus species on Sudan grass sown in alkaline sandy soil. $J$ King Saud Univ Sci 2, 101-6.

37. Koide RT, Mosse B (2004) A history of research on arbuscular mycorrhiza. Mycorrhiza 14, 145-63.

38. Azcón-Aguilar C, Barea JM (1997) Applying mycorrhiza biotechnology to horticulture: significance and potentials. Sci Hort 68, 1-24.

39. Bharadwaj DP, Lundquist PO, Alström S (2008) Arbuscular mycorrhizal fungal spore-associated bacteria affect mycorrhizal colonization, plant growth and potato pathogens. Soil Biol Biochem 40, 2494-501.

40. Vijayabharathi R, Sathya A, Gopalakrishnan S (2015) Plant growth-promoting microbes from herbal vermicompost. In: Egamberdieva D, Shrivastava S, Varma A (eds) Plant-Growth-Promoting-Rhizobacteria (PGPR) and Medicinal Plants, Soil Biology vol 42, Springer International Publishing, Switzerland, pp 71-88.

41. Blilou I, Bueno P, Ocampo JA, García-Garrido JM (2000) Induction of catalase and ascorbate peroxidase activities in tobacco roots inoculated with the arbuscular mycorrhizal Glomus mosseae. Mycol Res 104, 722-5.

42. Gianinazzi-Pearson V, Dumas-Gaudot E, Gollotte A, Tahiri-Alaoui A, Gianinazzi S (1996) Cellular and molecular defense-related root response to invasion by arbuscular mycorrhizal fungi. New Phytol 133 45-57.

43. Xie J, Schaich KM (2014) Re-evaluation of the 2,2-diphenyl-1-picrylhydrazyl free radical (DPPH) assay for antioxidant activity. J Agr Food Chem 62,
4215-60.

44. Maya MA, Matsubara Y (2013) Influence of arbuscular mycorrhiza on the growth and antioxidative activity in cyclamen under heat stress. Mycorrhiza 23, 381-90.

45. Mollavali M, Bolandnazar S, Nazemieh H, Zare F, Aliasgharzad N (2015) The effect of mycorrhizal fungi on antioxidant activity of various cultivars of onion (Allium cepa L.). Int J Biosci 6(1), 66-79.

46. Latef AAHA, Chaoxing H (2011) Arbuscular mycorrhizal influence on growth, photosynthetic pigments, osmotic adjustment and oxidative stress in tomato plants subjected to low temperature stress. Acta Physiol Plant 33, 1217-25.

47. Berruti A, Lumini E, Balestrini R, Bianciotto V (2016) Arbuscular mycorrhizal fungi as natural biofertilizers: Let's benefit from past successes. Front Microbiol 6, 1-13. 